\title{
BioLink
}

JURNAL BIOLOGI LINGKUNGAN, INDUSTRI, KESEHATAN

Available online http://ojs.uma.ac.id/index.php/biolink

\section{FAKTOR-FAKTOR YANG MEMPENGARUHI PERMINTAAN TANAMAN ANGGREK (ORCHIDACEAE) DI KOTA MEDAN}

\section{THE FACTORS AFFECTING DEMAND OF ORCHID PLANT (ORCHIDACEAE) IN MEDAN CITY}

\author{
Khairunnisa Rangkuti*, Muhammad Thamrin, Ilham Nurhanafi Siregar \\ Fakultas Pertanian, Universitas Muhammadiyah Sumatera Utara \\ *Corresponding author: E-mail: khairunnisarangkuti@vmail.com
}

\begin{abstract}
Abstrak
Tujuan penelitian ini adalah Untuk mengetahui pengaruh Harga, Selera Konsumen, Pendapatan dan Lokasi/Tempat terhadap Permintaan Tanaman Anggrek di Kota Medan, dan Untuk mengetahui Elastisitas Permintaan tanaman anggrek di Kota Medan. Data yang dikumpulkan adalah dari data Primer dan Data Sekunder.Berdasarkan hasil analisis pengujian secara statistik diperoleh nilai Multiple R sebesar $86.6 \%$. Nilai $\mathrm{F}$ tabel pada taraf kepercayaan signifikansi 0,05 adalah 2,76 dengan demikian $\mathrm{F}$ hitung $=18,801>\mathrm{F}$ tabel $=2,76$ pada taraf kepercayaan 95\%. Selanjutnya dalam melakukan pengujian uji T, untuk melihat pengaruh faktor pemintaan secara parsial terhadap permintaan tanaman anggrek, diperoleh nilai T-tabel 2,045 dengan tingkat kepercayaan 86,6 \%. Variabel X2, X3 dan X4 berpengaruh nyata Sedangkan Variabel X1 Tidak Berpengaruh nyata terhadap Permintaan (Y). Menganalisis nilai Elastisitas, Diperoleh Elastis Sebesar 3,395 > 1. Artinya tingkat Permintaan memiliki kepekaan terhadap Variabel independen (Selera, Pendapatan, dan Lokasi) sebesar 3,395.
\end{abstract}

Kata kunci: Permintaan, Konsumen, Tanaman Anggrek

\begin{abstract}
The purpose of this study was to determine the effect of prices, consumer tastes, income and location / place to Requests Orchid Plant in the city of Medan, and to know the Demand Elasticity of orchids in the city of Medan. The data collected from the data Primary and Secondary Data. Based on the results of testing statistical analysis obtained by value Multiple $R$ of $86.6 \%$. The value of F table at the level of 0.05 is thus calculated $F 2,76=18.801>$ F table $=2.76$ at 95\% confidence level. Furthermore, in testing T test, to see the effect of demand factors partially on the request of orchids, the value of the T-table 2.045 with a confidence level of $86.6 \%$. X2, X3 and X4 real impact While real variables X1 No Effect on Demand (Y). Analysing the value of Elasticity, Elastic Retrieved much as 3.395> 1. Demand level of sensitivity to the independent variable (tastes, income, and location) of 3.395.
\end{abstract}

Keywords: Demand, Consumer, Orchid Plant

How to Cite: Rangkuti, K., Thamrin, M., Siregar, I.N., 2018, Faktor-faktor yang Mempengaruhi Permintaan Tanaman Anggrek di Kota Medan, BioLink, Vol. 4 (2): Hal. 130-139 


\section{PENDAHULUAN}

Indonesia sebagai negara agraris dan memiliki kondisi aglokimat yang mendukung merupakan tempat potensial untuk mengembangkan komoditas hortikultura.Salah satu diantaranya adalah tanaman hias. Tanaman hias mempunyai prospek yang cukup cerah diindonesia, karena luasan lahan dan persyaratan kesuburan tanah yang dimanfaatkan untuk budidaya tanaman hias relatif kecil dibandingkan dengan luasan yang dimanfaatkan untuk jenis tanaman lainnya, serta tanaman hias memiliki nilai ekonomis yang tinggi dan dapat diterima dengan baik oleh masyarakat (Direktorat bina produksi, 2003)

Tanaman hias merupakan salah satu komoditi hortikultura yang terus meningkat permintaannya baik dipasar domestik maupun pasar internasional. Faktor-faktor penting yang mempengaruhi peningkatan permintaan akan kebutuhan tanaman hias adalah meningkatnya jumlah produk, meningkatnya pendapatan masyarakat, perkembangan sektor pariwisata, pertumbuhan industri bunga dan tanaman hias serta terciptanya suasana lingkungan yang nyaman, sejuk dan indah. Peningkatan jumlah permintaaan juga dipengaruhi oleh adanya perayaan hari-hari besar keagamaan seperti Idul Fitri, Natal, Imlek dan Tahun Baru (Warnaningsih, 2004)

Salah satu usaha tanaman hias yang bisa dilakukan adalah dengan membudidayakan tanaman anggrek. Menurut para ahli botani, di dunia terdapat lebih dari 43.000 spesies anggrek yang mencakup 800 genera dengan 75.000 hibrida terdaftar. Keanekaragaman jenis anggrek yang tinggi memberikan kemungkinan bagi pengembangan aneka jenis anggrek, baik sebagai bunga potong maupun sebagai tanaman hias berbunga (Iswanto. 2002)

Anggrek (Orchidaceae), termasuk dalam keluarga tanaman bungabungaan. Di seluruh dunia di perkiraan ada sekitar 25.000 spesies dan 800 genus anggrek (wagiman dan Sitanggang, 2005)

Anggrek merupakan bunga abadi.Artinya keberadaannya tidak mengenal musim dan disukai manusia sepanjang zaman. Karenanya, tidak mengherankan jika ilmuan, dan penghobiis anggrek terus melakukan penyilangan dari berbagai spesies atau berbagai jenis anggrek yang tujuannya menghasilkan anggrek baru dengan yang lebih menarik dan lebih indah (Parnata, 2005)

Anggrek merupakan tanaman bunga hias yang bunganya indah. Anggrek sudah dikenal sejak 200 tahun lalu dan sejak 50 tahun terakhir mulai dibudidayakan secara luas di Indonesia (Yulianti, 2013)

Jenis dan varietas anggrek sangat banyak.Namun, tidak satupun jenis anggrek yang pertumbuhannya bersifat parasit atau merugikan tanaman lainnya. Berdasarkan tempat tumbuhnya, sifat tumbuh anggrek dapat dibedakan 4 macam, yaitu Efifit, Semi Efifit, Terrestrik, dan Semi Terrestrik. Namun, diantara ragam dan jenis anggrek sebagian besar tumbuh secara efifit (Yos, 2006).

Bunga anggrek mempunyai daya tarik dilihat dari bentuk, warna maupun ukuran bunganya. Keindahan bunga anggrek akan menarik minat konsumen, sehingga bunga anggrek cukup 
berpeluang untuk dijadikan lahan usaha atau bisnis(Lestari, 1985).

Masa depan usaha budidaya terutama pada pembesaran anggrek sangat prosfektif dilihat dari penawaran dan permintaan, hingga saat ini persediaan produk anggrek lebih kecil dari pada permintaan pasar, di kebunkebun anggrek (nursery) selalu terjadi kekurangan produk anggrek yang akan di jual, baik botolan, kompot, seedling, tanaman remaja, maupun tanaman berbunga dalam pot (pot plant). Penyebab kekurangan produk anggrek tersebut adalah permintaan yang terus meningkat dan tidak disertai dengan penyediaan produk anggrek ini, dapat dikatakan bahwa lahan produksi anggrek belum bisa memenuhi permintaan pasar, berarti peluang usaha pembesaran anggrek sangat besar bagi para pendatang baru, setiap tahun beratusan jenis silangan anggrek baru selalu dihasilkan untuk melengkapi koleksi anggrek sekaligus untuk mengantisipasi tingkat kejenuhan pasar (Setiawan, 2009).

Pada masa sekarang ini bukan suatu rahasia lagi bahwa sebenarnya konsumen adalah raja sebenarnya, oleh karena itu produsen yang memiliki prinsip holistic marketing sudah seharusnya memperhatikan semua yang menjadi hak-hak konsumen (Nasution, 2002).

Hukum Permintaan pada hakekatnya merupakan suatuhipotesisyang menyatakan: "Semakin rendah harga suatu barang maka semakinbanyak permintaan terhadap barang tersebut (Sukirno, 2003).
Berdasarkan latar belakang yang telah dikemukakan, maka penulis tertarik terhadap permasalahan dalam penelitian ini yaitu bagaimana pengaruh harga, selera konsumen, pendapatan dan lokasi terhadap permintaan tanaman anggrek dikota medan dan berapa besar elastisitas permintaan tanaman anggrek dikota medan.

\section{METODE PENELITIAN}

Pemilihan lokasi penelitian ditentukan dengan metode purposive. Lokasi dipilih pada Dua usaha anggrek di Jl. H Adam Malik Desa Glugur Kota Kec. Medan Barat, Kota medan dan Satu usaha anggrek Di Jl. Lukah Kec. Medan Amplas Kota Medan.

Metode Penarikan Sampel menggunakan Insidental sampling. Yaitu, siapa saja yang secara kebetulan bertemu dengan peneliti dan melakukan pembelian dapat digunakan sebagai sampel dan bila dipandang orang yang kebetulan ditemui itu cocok sebagai sumber data.Dalam penelitian ini diambil 30 sampel dari 3 usaha dimana masing-masing adalah 10 responden.

Data yang digunakan dalam penelitian ini adalah data yang berupa data primer dan data sekunder. Data primer merupakan data yang diperoleh dari observasi langsung di lokasi dan wawancara dengan konsumen atau pembeli anggrek tersebut dengan pertanyaan-pertanyaan yang telah disiapkan sebelumnya. Sedangkan data sekunder diperoleh dari literatur atau buku-buku yang berpengaruh atau berkaitan dengan penelitian ini dan dari lembaga-lembaga atau dinas-dinas terkait. 
Perumusan masalah Pertama yaitu mengetahui pengaruh Harga, Selera Konsumen, Pelayanan, Lokasi/ Tempat dianalisa dengan menggunakan analisis regresi linier berganda, dengan rumus:

$\mathrm{Y}=\mathrm{a}+\mathrm{b} 1 \mathrm{x} 1+\mathrm{b} 2 \mathrm{x} 2+\mathrm{b} 3 \mathrm{x} 3+\mathrm{b} 4 \mathrm{x} 4+\mathrm{e}$

Dimana:

$\mathrm{Y}=$ Permintaan

$\mathrm{a}=$ Konstanta/ Intercept

$\mathrm{x} 1=$ Harga Anggrek (Rp/Pot)

x2= Selera Konsumen (Dummy Variabel)

Ketegori :

Suka $\quad=1$

Tidak Suka $\quad=0$

x3= Pendapatan konsumen (Rp/bulan)

$\mathrm{x} 4=$ Lokasi (Dummy Variabel)

Kategori :

Strategis $=1$

Non Strategis $=0$

$\mathrm{b}=$ Koefisien Rregresi

$\mathrm{e}=$ error

Pengambilan Keputusan:

Jika : thit < t table, tolak $\mathrm{H} 1$; terima $\mathrm{HO}$ thit $>$ t table, tolak $\mathrm{H} 0$; terima $\mathrm{H} 1$ HO : tidak ada pengaruh

H1 : ada pengaruh

Untuk pemecahan masalah kedua yaitu dengan menggunakan analisis elastisitas. Yaitu dengan mengukurnya melalui tiga situasi dalam tingkat Return To Scale berikut ini :

Rumus :

$$
\mathrm{B} 1+\mathrm{B} 2+\mathrm{B} 3+\mathrm{B} 4=1,>1,<1
$$

Dimana :

$\begin{array}{ll}\text { B1 } & =\text { Nilai elastisitas Harga } \\ \text { B2 } & =\text { Nilai elastisitas Selera } \\ \text { B3 } & =\text { Nilai elastiitas Pendapatan } \\ \text { B4 } & \text { = Nilai elastisitas Lokasi }\end{array}$

Decreasing Return To Scale, bila $(b 1+b 2+b 3+b 4)<1$. Dalam keadaan demikian, dapat diartikan bahwa proporsi penambahan faktor yang mempengaruhi permintaan tidak mempengaruhi proporsi penambahan Permintaan.

Constant Return To Scale, bila $(\mathrm{b} 1+\mathrm{b} 2+\mathrm{b} 3+\mathrm{b} 4)=1$. Dalam keadaan demikian penambahan faktor permintaan akan proporsional dengan penambahan Permintaan yang diperoleh.

Increasing Returns To Scale, bila $(\mathrm{b} 1+\mathrm{b} 2+\mathrm{b} 3+\mathrm{b} 4)>1$. Ini artinya bahwa proporsi penambahan faktor Permintaan akan menghasilkan tambahan Permintaan yang proporsinya lebih besar.

Kriteria dari Elastis adalah :

Permintaan Inelastis Sempurna $\quad E=0$

Permintaan Inelastis $\quad \mathrm{E}<1$

Permintaan Elastis Uniter $\quad \mathrm{E}=1$

Permintaan Elastis $\quad E>1$

Permintaan Elastis Sempurna $\quad \mathrm{E}=\sim$

\section{HASIL DAN PEMBAHASAN}

\section{Deskripsi Lokasi Penelitian}

Lokasi usaha yang diteliti di kota medan adalah 3 tempat usaha tanaman anggrek. lokasi ini diambil dari dua kecamatan yaitu 2 usaha tanaman anggrek di kecamatan medan barat dan satu usaha tanaman anggrek dikecamatan medan amplas.

\section{Analisis Regresi Linear Berganda}

Berdasarkan hasil analisis pengujian secara statistik diperoleh nilai Multiple R sebesar 0,866 yang mengartikan bahwa secara menyeluruh ada hubungan yang sangat erat antara Harga, Selera Konsumen, Pendapatan dan Lokasi terhadap Permintaan Tanaman Anggrek di Kota Medan sebesar $86,6 \%$. 
Tabel1. Analisis Regresi Linier Berganda Antara Harga, Selera Konsumen, Pendapatan dan Lokasi terhadap Permintaan Tanaman Anggrek di Kota Medan.

\begin{tabular}{llll}
\hline Variabel & Nilai Koefesien & $\begin{array}{l}\text { Standart } \\
\text { Error }\end{array}$ & Sig \\
\hline Harga X & & 0,000 & 0,001 \\
Selera X $_{2}$ & $-5,581$ & 0,208 & 0,012 \\
Pendapatan X $_{3}$ & 0,559 & 0,000 & 0,001 \\
Lokasi X & 7,835 & 0,191 & 0,005 \\
Konstanta & 0,582 & 0,900 & 0.001 \\
Multiple R & 3,266 & & \\
R-square & $0,866^{\mathrm{a}}$ & & \\
Sig F & 0,751 & & \\
Signifikansi $(\alpha)$ & 18,801 & & \\
\hline
\end{tabular}

Sumber : Data Primer, 2016

Dari tabel diatas dapat diketahui bahwa persamaan regresi linier berganda sebagai berikut :

$$
\mathrm{Y}=3,266-5,581 \mathrm{X}_{1}+0,559 \mathrm{X}_{2}+7,835 \mathrm{X}_{3}+0,582 \mathrm{X}_{4}
$$

Interpretasi:

a. Nilai Konstanta 3,266 yang artinya bahwa jika Harga, Selera Konsumen, Pendapatan dan Lokasi bernilai 0 maka jumlah permintaannya sebesar 3,266.

b. Nilai Koefisien regresi $\mathrm{X}_{1}$ sebesar $-5.581 \%$ menunjukkan bahwa apabila setiap kenaikan Harga sebesar 1\%, dengan asumsi variabel bebas lainnya dianggap konstan, maka akan menurunkan Permintaan tanaman anggrek sebesar $-5,581 \%$.

c. Koefisien regresi $\mathrm{X}_{2}$ sebesar 0.559\% menunjukkan bahwa apabila setiap kenaikan Selera sebesar $1 \%$ dengan asumsi variabel bebas lainnya dianggap konstan, maka akan
menaikkanPermintaan tanaman anggrek sebesar 0,559\% .

d. Koefisien regresi $\mathrm{X}_{3}$ sebesar 7,835\% menunjukkan bahwa apabila setiap kenaikan Pendapatan sebesar 1\% dengan asumsi variabel bebas lainnya dianggap konstan, maka akan menaikkanPermintaan tanaman anggrek sebesar 7,835\% .

e. Nilai Koefisien regresi $\mathrm{X}_{4}$ sebesar $0,582 \%$ menunjukkan bahwa apabila setiap kenaikan tingkat Strategis Lokasi sebesar 1\%, dengan asumsi variabel bebas lainnya dianggap konstan, maka akan menaikkan Permintaan tanaman anggrek sebesar $0,582 \%$. 


\section{Koefisien Determinasi}

Tabel2. Nilai koefisien Determinasi

\begin{tabular}{lllll}
\hline & & & Adjusted & $\mathrm{R}$ \\
Model & $\mathrm{R}$ & $\mathrm{R}$ Square & Square & Std. Error of the Estimate \\
\hline 1 &, $866^{\mathrm{a}}$ &, 751 &, 711 &, 496 \\
\hline
\end{tabular}

Predictors: (Constant), Jarak_lokasi, Selera, Harga, Pendapatan

Dependent Variable: Permintaan

Berdasarkan hasil pengolahan data SPSS untuk koefisien determinasi (R2) pada tabel model summary diatas dihasilkan nilai R Square sebesar 0,866 (86,6\%) yang artinya 86,6 \% Variabel Permintaan $(\mathrm{Y})$

\section{Uji F Berdasarkan Hasil Output SPSS}

Tabel 3. Uji Simultan

\begin{tabular}{lccccc}
\hline \multirow{2}{*}{ Model } & \multicolumn{5}{c}{ ANOVA $^{\text {a }}$} \\
& $\begin{array}{c}\text { Sum of } \\
\text { Squares }\end{array}$ & Df & Mean & F & Sig. \\
& \multicolumn{3}{c}{ Square } \\
$\begin{array}{l}\text { Regression } \\
\text { Residual }\end{array}$ & 18,538 & 4 & 4,634 & 18,801 & $0,000^{\text {b }}$ \\
& 6,162 & 25 & 0,246 & & \\
\hline Total & 24,700 & 29 & & & \\
\hline
\end{tabular}

Data Primer Olahan 2016

Setelah dilakukan penganalisaan dengan menggunakan program SPSS maka dapat didapat output uji signifikansi simultan/ bersama-sama (uji statistik F) menghasilkan nilai $\mathrm{F}$ hitung sebesar 18,801. Nilai F tabel pada taraf kepercayaan signifikansi 0,05 adalah 2,76 dengan demikian $\mathrm{F}$ hitung $=$ $18,801>\mathrm{F}$ tabel $=2,76$ pada taraf kepercayaan 95\%. Artinya bahwa ada pengaruh yang nyata antara variabel bebas (Harga, Selera, Pendapatan dan Lokasi) terhadap variabel terikat Permintaan tanaman anggrek.
Mampu dijelaskan oleh variabel Harga, Selera Konsumen, Pendapatan dan Lokasi. Sedangkan Selebihnya 13,4 \% dijelaskan oleh variabel lain yang tidak dimasukkan kedalam model. 
Rangkuti, K., Thamrin, M., Siregar, I.N., Faktor-faktor yang Mempengaruhi Permintaan Tanaman

\section{Uji Parsial}

Tabel4. Uji Parsial

\begin{tabular}{lccccc}
\hline \multirow{2}{*}{ Model } & \multicolumn{2}{c}{$\begin{array}{c}\text { Unstandardized } \\
\text { Coefficients }\end{array}$} & $\begin{array}{c}\text { Standardized } \\
\text { Coefficiens }\end{array}$ & t & Sig. \\
\cline { 2 - 5 } & $\mathrm{B}$ & Std. Error & Beta & & \\
\cline { 2 - 5 } (Constant) & 3,266 & 0,900 & & 3,628 & 0,001 \\
Harga & $-5,581$ & 0,000 & $-0,417$ & $-3,866$ & 0,001 \\
Selera & 0,559 & 0,208 & 0,290 & 2,695 & 0,012 \\
Pendapatan & 7,835 & 0,000 & 0,409 & 3,748 & 0,001 \\
Lokasi & 0,582 & 0,191 & 0,318 & 3,041 & 0,005 \\
\hline
\end{tabular}

Data Primer Olahan 2016

Pengambilan Keputusan:

Jika : thit < t table, tolak $\mathrm{H} 1$; terima $\mathrm{HO}$

thit $>\mathrm{t}$ table, tolak $\mathrm{H} 0$; terima $\mathrm{H} 1$

HO : tidak ada pengaruh

H1 : ada pengaruh

Dalam melakukan pengujian uji T, untuk melihat pengaruh faktor pemintaan secara parsial terhadap permintaan tanaman anggrek, dengan mencari nilai:

Uji $\mathrm{T}=\mathrm{n}-\mathrm{k}$ (variabel bebas)

30-4

$=26$

@ $=0.05$

Diperoleh nilai T-tabel 2,056 melihat dari tabel $\mathrm{T}$ dengan tingkat kepercayaan 86,6 \%. Berikut adalah penjelasannya:

a. $\mathrm{X}_{1}$ : Berdasarkan Tabel untuk uji parsial variabel Harga $\left(\mathrm{X}_{1}\right)$ diperoleh nilai T-hitung -3,866< nilai T-tabel 2,056 dan sig. 0,001< 0,05 sehingga $\mathrm{H}_{1}$ ditolak dan $\mathrm{H}_{0}$ diterima artinya secara parsial Harga $\left(\mathrm{X}_{1}\right)$ Tidak berpengaruh signifikan atau nyata terhadap permintaan tanaman anggrek. Hal ini disebabkan harga yang Tidak berpengaruh nyata terhadap

permintaan tanaman anggrek. Konsumen membeli Anggrek tidak

melihat seberapa besar pengaruh atau perubahan Anggrek, karena pada umumnya konsumen tanaman anggrek yang diteliti adalah penghobiis dan prestise.Sehingga, konsumen membeli berapapun harga anggrek tersebut bila ada kebutuhan atau juga hobbinya. Hal ini juga bisa berarti dari segi $t$ hitung dan $t$ tabel kurang berpengaruh terhadap permintaan kerena $\mathrm{t}$ hitung $<\mathrm{t}$ tabel.

b. $\mathrm{X}_{2}$ : Berdasarkan Tabel untuk uji parsial variabel Selera diperoleh nilai T-hitung 2,695 >2,056 nilai Ttabel dan sig. 0,012<0,05 sehingga $\mathrm{H}_{0}$ ditolak dan $\mathrm{H}_{1}$ diterima artinya secara parsial Selera $\left(\mathrm{X}_{2}\right)$ berpengaruh signifikan atau nyata terhadap permintaan tanaman anggrek. Dari variabel selera bagi konsumen sangat berpengaruh terhadap permintaannya. Ini juga dikarenakan sebagai penghobiis pada umumnya. Dan pada khususnya penghobiis memiliki selera dan bervariasi. Bahkan dari segi uji $\mathrm{T}$, juga berpengaruh nyata 
dengan keputusan $t_{\text {hit }}>t$ table, tolak $\mathrm{H} 0$ dan terima $\mathrm{H} 1$.

c. $\mathrm{X}_{3}$ : Berdasarkan Tabel untuk uji parsial variabel Pendapatan diperoleh nilai T-hitung 3,748 $>2,056$ nilai T-tabel dan sig. 0,001< 0,05 sehingga $\mathrm{H}_{0}$ ditolak dan $\mathrm{H}_{1}$ diterima artinya secara parsial Pendapatan $\left(\mathrm{X}_{3}\right)$ berpengaruh signifikan atau nyata terhadap permintaan tanaman anggrek. Dari segi nilai uji $\mathrm{T}$ juga berpengaruh nyata dengan keputusan $t_{\text {hit }}>t$ table, tolak $\mathrm{H} 0$ dan terima $\mathrm{H} 1$. Hal ini membuktikan bahwa dari kriteria responden memiliki pendapatan yang baik sehingga konsumen tanaman anggrek dapat membelinya dengan sesuai pendapatan. Semakin tinggi pendapatan semakin banyak permintaan terhadap tanaman anggrek yang dibeli. Berdasarkan Pendapatan konsumen yang diteliti nilainya bervariasi. Nilai pendapatan tertinggi adalah senilai Rp. 20.000.000 dan terendah adalah Rp. 5.000.000/ Bulan. Sehingga Penghasilan penghobiis tergolong tingkat penghasilan yang baik.

d. $\mathrm{X}_{4}$ : Berdasarkan Tabel untuk uji parsial variabel Lokasi diperoleh nilai T-hitung 3,041>2,056 nilai Ttabel dan sig. 0,005 $<0,05$ sehingga $\mathrm{H}_{0}$ ditolak dan $\mathrm{H}_{1}$ diterima artinya secara parsial Lokasi (X) berpengaruh signifikan atau nyata terhadap permintaan tanaman anggrek. Dari segi nilai uji $\mathrm{T} \mathrm{t}_{\mathrm{hit}}<\mathrm{t}$ table, tolak $\mathrm{H} 0$; terima $\mathrm{H} 1$. Ini menyatakan bahwa variabel Lokasi berpengaruh nyata terhadap permintaan. Dari kriteria Lokasi, pada umumnya sangat baik dan strategis. Dari hasil penelitian terhadap responden dapat disimpulkan bahwa Lokasi Produsen tanaman anggrek dinilai Strategis, sehingga Lokasi sangat berpengaruh nyata terhadap permintaan tanaman anggrek. Terutama, Lokasi produsen tanaman anggrek sangat strategis yaitu dekat keramaian dan mudah dijangkau bahkan wilayahnya termasuk dekat dengan Pusat Kota Medan.

\section{Elastisitas Permintaan}

Ed $=-5,581 \quad \mathbf{X}_{1}+0,559 \quad \mathbf{X}_{2}+7,835 \mathbf{X}_{3}+$ $0,582 \mathrm{X}_{4}$

Dalam Mencari nilai Elastisitas yaitu dengan caramenjumlahkan koefisien dari masing masing faktor permintaan $\left(\mathrm{b}_{1}+\mathrm{b}_{2}+\mathrm{b}_{3}+\mathrm{b}_{4}\right)$ yaitu-5,581 + $0,559+7,835+0,582=3,395$ dalam keadaan demikian $\left(\mathrm{b}_{1}+\mathrm{b}_{2}+\mathrm{b}_{3}+\mathrm{b}_{4}\right)>1$ atau 3,395 > 1 . Jadi, dapat diintreprestasikan bahwa tingkat Elastisitas Permintaan memiliki kepekaan terhadap Variabel independen (Selera, Pendapatan, dan lokasi) sebesar 3,395.Tingkat Return To Scalenya adalahIncreasing Returns To Scale, bila $\left(b_{1}+b_{2}+b_{3}+b_{4}\right)>1$. Ini artinya proporsi penambahan variable permintaanakan menghasilkan tambahan Permintaan yang proporsinya lebih besar. Permintaan anggrek dikatakan elastis, hal ini dikarenakan anggrek merupakan barang mewah atau bisa disebut dengan sebagai kebutuhan tersier yang artinya variabel independent berpengaruh nyata terhadap variabel dependen 
Menurut Lempang (2012), aren merupakan pohon yang hampir semua bagian fisik maupun produksinya dapat dmanfaatkan dan memilki nilai ekonomi. Produksi aren seperti buah, nira dan tepung sudah dimanfaatkan sejak lama. Saat ini yang masih perlu pengembangan lebih lanjut adalah pemanfaatan nira aren untuk cuka, etanol dan nata.

\section{SIMPULAN}

Adapun kesimpulan dari penelitian yang dilakukan adalah :

Berdasarkan hasil analisis pengujian secara statistik diperoleh nilai Multiple $\mathrm{R}$ sebesar 0,866 yang mengartikan bahwa secara menyeluruh ada hubungan yang sangat erat antara Harga, Selera Konsumen, Pendapatan dan Lokasi terhadap Permintaan Tanaman Anggrek di Kota Medan sebesar 86,6 \%. Secara Parsial, dari hasil olahan data dapat dilihat keterkaitan antara variabel bebas secara satu persatu dengan variabel terikat permintaan tanaman anggrek. Selanjutnya dalam melakukan pengujian uji $\mathrm{T}$, untuk melihat pengaruh faktor pemintaan secara parsial terhadap permintaan tanaman anggrek, diperoleh nilai T-tabel 2,045 dengan tingkat kepercayaan 86,6 \%. Variabel X1, X2, X3 dan X4 berpengaruh nyata terhadap Permintaan (Y).

Tingkat Elastisitas Permintaan memiliki kepekaan terhadap Variabel independen (Harga, Selera, Pendapatan, dan Lokasi) sebesar 3,395. Tingkat ReturnTo Scalenya adalahIncreasing Returns To Scale, bila $\left(\mathrm{b}_{1}+\mathrm{b}_{2}+\mathrm{b}_{3}+\mathrm{b}_{4}\right)>1$. Ini artinya proporsi penambahan
variabelPermintaanakan menghasilkan tambahan Permintaan yang proporsinya lebih besar. Permintaan anggrek dikatakan elastis, hal ini dikarenakan anggrek merupakan barang mewah atau bisa disebut dengan sebagai kebutuhan tersier yang artinya variabel independent berpengaruh nyata terhadap variabel dependen .

\section{DAFTAR PUSTAKA}

A. Z. Nasution, Hukum Perlindungan Konsumen, Jakarta: Diadit Media, 2002.

Direktorat Bina Produksi Hortikultura. 2003. Informasi Teknis Norma Budidaya Anggrek. Jakarta.

Iswanto, H. 2002. Petunjuk Perawatan Anggrek.Agromedia Pustaka, Jakarta.

Lestari, S.S. 1985. Mengenal dan Bertanam Anggrek. Aneka Ilmu, Semarang.

Parnata. A,S. 2005. Budidaya Dan Perawatan Anggrek. Agromedia Pustaka, Jakarta.

Setiawan, H. 2009, Usaha Pembesaran Anggrek. Penebar Swadaya. Jakarta.

Sukirno, S. 2003, "Pengantar Teori Mikro Ekonomi". PT. Salemba Empat. Jakarta.

Yulianti, E. 2013 http:// staff.uny.ac.id/ sites/ default/ files/ pengabdian/ evy-yulianti$2013 \mathrm{msc} /$ budidaya - tanaman anggrek.pdf 8 juni 2016.

Yos.S, 2006. Peluang Bisnis Anggrek. Penebar Swadaya Jakarta.

Wagiman \& Sitanggang, 2005.Menanam dan Membungakan Anggrek di Pekarangan Rumah. Agromedia Pustaka.

Warnaningsih,WFS.2004http:/repository.uinjkt. ac.id/dspace/bitstream/123456789/11340/ wahyu\%ofajar\%2osyahdwi\%2owarnannin gsih-fst.pdf. diakses 16 april 2015. 